\title{
Studies on Zinc (II) Adsorption Using Alisma Plantago Aquatica
}

\author{
E. R. Ushakumary and G. Madhu
}

\begin{abstract}
Adsorption is an effective method to remove heavy metals from wastewater. Alisma Plantago Aquatica was used as an adsorbent to remove $\mathrm{Zn}$ (II) from aqueous solution. The equilibrium adsorption were analysed using three isotherm models. The adsorption kinetics followed the pseudo-second order model. Isotherm studies have been used to determine the thermodynamic parameters of the process. Temperature change in the range $20-50^{\circ} \mathrm{C}$ affected the adsorption capacity. From enthalpy data revealed that the adsorption is endothermic in nature. IR spectrum analysis suggested the presence of hydroxyl, carboxyl and carbonyl groups which are participating in the adsorption of metal ions. The performance of continuous flow packed bed adsorption systems with the biomass was evaluated by plotting the breakthrough curves. It was observed that the breakthrough was strong function of the flow rates and the height of the packed bed. The zinc removal yield decreased with increasing flow rates and initial zinc concentration. Adam Bohart and Wolborska models were applied to the experimental data from dynamic studies on packed bed and were observed to fit the data well with good correlations. The model parameters including the mass transfer coefficient and kinetic parameter were estimated.
\end{abstract}

Index Terms-Adsorption, heavy metal, isotherm kinetics, thermodynamic.

\section{INTRODUCTION}

Due to rapid development of industrial activities in recent years, the levels of heavy metals in water system have substantially increased over time. Heavy metals can easily enter the food chain because of their high solubility in water. Due to their toxic effect and accumulation tendency throughout the food chain and the heavy metals pollution represents an important problem, with human health and serious ecological consequences. It is therefore essential to remove heavy metals from industrial waste waters and drinking water.

Zinc is essential in small quantity but when exceeds the prescribed limit it has also detrimental effect on human health. World Health Organization has set a provisional limit of $5 \mathrm{mg} / \mathrm{l}$ for zinc. It is mostly found in the inorganic form particularly in +2 states. Zinc is used in the process of galvanization,pigment formation,stabilizers, thermoplastics, alloys and batteries. During the metallurgical processes, some amounts of metals are also released into the water bodies.

Manuscript received April 10, 2013; revised July 11, 2013.

E. R. Ushakumary is with the Department of Chemical Engineering, Government Engineering College, Kozhikode, Kerala, India (e-mail: ushashik@rediffmail.com).

G. Madhu is with the Chemical Engineering Group, School of Engineering, Cochin University of Science and Technology, Kochi -682 022 , Kerala, India.
Due to their high toxicity, industrial wastewaters containing heavy metals are strictly regulated and must be treated before being discharged in to the environment. A number of technologies have been developed over the years to remove heavy metals from industrial waste water. The most important technologies include chemical precipitation, coagulation process, membrane filtration process etc [1]. These methods are generally expensive, complicated and time consuming. The major advantages of an adsorption system for water pollution control are less investment in terms of both initial cost and land, simple design, easy operation, and the absence of the effect of toxic substances compared to conventional methods [2], [3]. In the last few decades, alternative sorbents for the treatment of heavy metal contamination have been investigated [4]-[7]. There is a large volume of literature relating to the performance of different biosorbents for the removal of variety of heavy metals [8]-[11].

Numerous waste biomass sources are available in nature in which some experimental adsorption properties have been reported e.g rice husk[12 ], saw dust [13]-[15], tea and coffee waste [16]-[18],orange peel [19] peanut shells[20], activated carbon [21]-[22] dry tree leaves and barks [23]-[25]. When compared with other low cost adsorbents, the results of the present study indicate that adsorbent prepared from Alisma plantago aquatica has better adsorption capacity in almost all cases.

Adsorption of heavy metal ions occurs as a result of physicochemical interaction, mainly ion exchange or complex formation between metal ions and the functional groups present on the cell surface.

The main aim of this work is to study the behaviour of a specific biomass. This paper works on the amount of $\mathrm{Zn}$ ions that uptake by Alisma Plantago Aquatica by Langmuir and Freundlich isotherm equations for equilibrium, and investigates the kinetic and thermodynamic by different models. The study was carried out in a laboratory fixed bed continuous column using suitable mathematical models [26], [27].

\section{MAterials AND METHODS}

\section{A. Adsorbent and Instrument.}

The experiments were carried out using the adsorbent Alisma Plantago Aquatica (AP) .The adsorbent samples were collected from the near by locality and washed several times with distilled water to remove dust and other impurities. After drying, it is then ground using domestic mixer and sieved to 250 mesh size. The sample is washed with distilled water to remove colour and dried in an oven at $60^{\circ} \mathrm{C}$ for 24 
hours. The dried sample was stored in airtight bottles for further use with out any chemical or physical treatment.

All reagents used in this study were of analytical grade obtained either from Merck Germany. Stock solution of zinc was prepared by zinc nitrate salts in double distilled water. $\mathrm{Zn}$ (II) solution of different concentrations were obtained by diluting the stock solution.

Analysis of each $\mathrm{Zn}$ (II) remaining in solution and initial metal concentration was determined using Atomic absorption spectrophotometer (Thermofisher iCE:3000).

FT-IR Spectra were obtained on a Perkin Elmer (Spectrum two) spectrometer.

\section{RESULTS AND DISCUSSION}

\section{A. Adsorption Kinetics}

To study the adsorption kinetics of $\mathrm{Zn}$ (II) onto Alisma Plantago Aquatica, first order kinetics and second order kinetics were applied to the batch experimental data. In order to define the adsorption kinetics of heavy metal ions, the kinetic parameters for the adsorption process were studied for contact times ranging between 1 and $150 \mathrm{~min}$. The kinetics in most cases follows the first order rate equation.

$$
\frac{d q}{d t}=k_{1}\left(q_{e}-q\right)
$$

where $q_{e}$ and $q$ are the adsorption capacity at equilibrium and at time $\mathrm{t}$ respectively, and $\mathrm{k}_{1}$ is the rate constant of the pseudo first order adsorption process. The integrated linear form of Eq.(1) can be expressed as follows:

$$
\log \left(q_{e}-q\right)=\log \left(q_{e}\right)-\frac{k_{1}}{2.303} t
$$

Plot of $\log \left(q_{e^{-}} q\right)$ vs. $\mathrm{t}$ gives a straight line for first order adsorption kinetics and the rate constant $k_{l}$ is computed from the plot.

The sorption data was also studied by second order kinetics

$$
\frac{d q}{d t}=k_{2}\left(q_{e}-q\right)^{2}
$$

where $k_{2}$ is the second order rate constant.

After integration,

$$
\frac{1}{q_{e}-q}=\frac{1}{q_{e}}+k_{2} t
$$

This can be written in the linear form on further simplification

$$
\frac{t}{q}=\frac{1}{k_{2} q_{e}^{2}}+\frac{t}{q_{e}}
$$

The applicability of this equation can be studied by a plot of $t / q$ vs. $t$ and the rate constant $k_{2}$ and $q$ are obtained from the plot.

The intra particle diffusion model was used to understand the diffusion mechanism. Intra particle diffusion was characterized using the relationship between specific sorption $(q)$ and the square root of time $\left(t^{1 / 2}\right)$

$$
q=k_{d} t^{1 / 2}
$$

where $k_{d}$ is the intra-particle diffusion rate constant and the rate constant $k_{d}$ directly evaluated from the slope of the regression line.

The second order equation appeared to be the better fitting model than other models because it has higher $R^{2}$ value. The values of the first order, second order and Intra particle diffusion kinetic models are tabulated in the Table I.

TABLE I: KINETICS PARAMETERS FOR THE ADSORPTION OF ZN(II) ONTO ALISMA PLANTAGO AQUATICA

\begin{tabular}{|l|l|l|l|l|l|l|l|l|}
\hline$q_{\exp }(\mathrm{mg} / \mathrm{g})$ & \multicolumn{3}{|l|}{ First order } & \multicolumn{3}{l|}{ Second order } & \multicolumn{2}{l|}{ Intra Particle } \\
\hline & $R^{2}$ & $q_{\text {calc }}$ & $k_{1}$ & $R^{2}$ & $q_{\text {calc }}$ & $k_{2}$ & $k_{d}$ & $R^{2}$ \\
\hline 14.73 & 0.84 & 3.78 & 0.033 & 0.999 & 15.27 & 0.016 & 0.302 & 0.918 \\
\hline
\end{tabular}

\section{B. Adsorption Isotherms}

During adsorption a rapid equilibrium is established between adsorbed heavy metal ions on AP $\left(q_{e q}\right)$ and unadsorbed heavy metal ions in solution $\left(C_{e q}\right)$. This equilibrium can be analysed by mathematical representation called adsorption isotherms.

The adsorption coefficient $q$ is calculated from the expression

$$
q=\frac{V\left(C_{i}-C_{f}\right)}{M}
$$

where $V$ is the volume of the solution, $C_{i}$ and $C_{f}$ are initial and equilibrium concentrations and $M$ is the dry mass of adsorbent.

The most widely used isotherm equation for modeling the equilibrium is the Langmuir equation which is valid for monolayer sorption on to a surface with a finite number of identical sites and is given by equation

$$
q=\frac{q_{\mathrm{max}} b C_{f}}{\left(1+b C_{f}\right)}
$$

where $q_{\max }$ is the maximum amount of the metal ion per unit weight of the adsorbent to form a complete monolayer on the surface bound at high $C_{f}$ and $b$ is a constant related to the affinity of the binding sites $\mathrm{q}_{\max }$ represents a practical limiting adsorption capacity when surface is fully covered with metal ions and assists in the comparison of adsorption performance particularly in cases where the sorbent did not reach its full saturation in experiments. $q_{\max }$ and b can be determined from the linear plot of $C_{f} / q$ versus $C_{f}$. The linearized form of this model equation is given as

$$
\frac{C_{f}}{q}=\frac{C_{f}}{q_{\max }}+\frac{1}{b q_{\max }}
$$

The empirical Freundlich model also considers mono molecular layer coverage of solute by the adsorbent. However, it assumes the adsorbent has a heterogeneous surface so that binding sites are not identical. This model 
takes the following form for a single component adsorption.

$$
q=K C_{f}^{1 / n}
$$

where $K$ and $\mathrm{n}$ are the Freundlich constants characteristic of the system. $K$ and $n$ are indicators of adsorption capacity and adsorption intensity respectively. Through the Freundlich isotherm is more widely used, it provides no information on the monolayer adsorption capacity, in contrast to the Langmuir model.

$$
\log q=\log K+\frac{1}{n} \log C_{f}
$$

Langmuir and Freundlich isotherms are insufficient to explain the physical and chemical characteristics of adsorption. Dubinin - Radushkevich (D-R) isotherm is commonly used to describe the adsorption isotherms of single solute systems.

The D-R isotherm is expressed as

$$
\begin{gathered}
q=q_{\max } \exp \left(-B\left[R T \ln \left(1+\frac{1}{C_{f}}\right)\right]^{2}\right) \\
\ln q=\ln q_{\max }-B e^{2}
\end{gathered}
$$

where $B$ is a constant related to the adsorption energy, $R$ is the gas constant $\left(8.314 \times 10^{-3} \mathrm{~kJ} / \mathrm{molK}\right)$ and $T$ is the absolute temperature

$$
\begin{gathered}
e=R T \ln \left(1+\frac{1}{C_{f}}\right) \\
E=\frac{1}{(2 B)^{0.5}}
\end{gathered}
$$

Study of variation of the initial heavy metal concentration at a fixed amount of $0.25 \mathrm{~g} / 100 \mathrm{ml}$ was carried out at room temperature. Adsorption isotherms show the distribution of solute between the liquid and solid phases and can be described by several mathematical relationships such as the standard Langmuir and Freundlich models. The linearized Langmuir and Freundlich adsorption isotherms obtained shown in the Table II with the values of linear regression coefficients. In view of the values of the linear regression coefficients, both the models fitted very well to the sorption data in the studied concentration range.

An adsorption isotherm is characterized by certain constants the values of which express the surface properties and affinity of the sorbent. The Freundlich constants $k$ and $1 / n$ are adsorption capacity and adsorption intensity are determined for $\mathrm{Zn}$ (II) at all values of temperature. The Langmuir constants of $q_{\max }$ and $b$ were determined from $C_{f} / q$ versus $C_{f}$ plot. The applicability of both Langmuir and Freundlich isotherms implies that both monolayer adsorption and heterogeneous surface conditions exist under the experimental conditions used.
TABLE II: COMPARISON OF FTIR BAND POSITIONS OF RAW ALISMA PlaNTAGO AQUATICA (AP) BEFORE AND AFTER ZINC ION ADSORPTION IN WAVE NUMBER $\left(\mathrm{CM}^{-1}\right)$

\begin{tabular}{|l|l|l|l|l|l|l|l|l|l|}
\hline $\mathrm{T}(\mathrm{K})$ & \multicolumn{3}{|l|}{ Langmuir model } & \multicolumn{3}{l|}{ Freundlich model } & \multicolumn{3}{l|}{ Dubinin Radushkevich } \\
\hline & $\mathrm{R}^{2}$ & $\mathrm{q}_{\max }$ & $\mathrm{b}$ & $\mathrm{R}^{2}$ & $1 / \mathrm{n}$ & $\mathrm{K}$ & $\mathrm{R}^{2}$ & $\mathrm{q}_{\max }$ & $\mathrm{E}$ \\
\hline 293 & 0.99 & 24.27 & 0.07 & 0.99 & 0.59 & 2.18 & 0.88 & 14.87 & 0.49 \\
\hline 303 & 0.99 & 25.12 & 0.08 & 0.99 & 0.59 & 2.36 & 0.83 & 14.92 & 0.59 \\
\hline 313 & 0.99 & 25.83 & 0.09 & 0.995 & 0.58 & 2.74 & 0.90 & 16.34 & 0.65 \\
\hline 323 & 0.995 & 26.67 & 0.11 & 0.997 & 0.56 & 3.19 & 0.85 & 16.56 & 0.81 \\
\hline
\end{tabular}

\section{Thermodynamic Parameters}

The experiments were conducted at different temperatures $\left(20,30,40,50^{\circ} \mathrm{C}\right)$. The thermodynamic parameters such as change in standard free energy $\left(\Delta \mathrm{G}^{\circ}\right)$, enthalpy $\left(\Delta \mathrm{H}^{\circ}\right)$ and entropy $\left(\Delta S^{\circ}\right)$ can be determined by using the following equations:

$$
\begin{aligned}
& \Delta G=-R T \ln b \\
& \ln b=\frac{\Delta S}{R}-\frac{\Delta H}{R T} \\
& \Delta \mathrm{G}=\Delta \mathrm{H}-\mathrm{T} \Delta S
\end{aligned}
$$

where $\mathrm{R}(8.314 \mathrm{~J} / \mathrm{mol} \mathrm{K})$ is the gas constant, $\mathrm{T}(\mathrm{K})$ the absolute temperature and $b(\mathrm{~L} / \mathrm{mol})$ is the thermodynamic equilibrium constant. A plot of Gibbs free energy $(\Delta G)$ versus temperature was found to be linear. The values of enthalpy and entropy were obtained from the slope and intercept of the plots. Positive values of $\Delta \mathrm{H}$ indicate that the adsorption of metal ions on the adsorbent is endothermic. The negative values of $\Delta \mathrm{G}$ reveal the feasibility and spontaneous nature of the process. This results also supports the adsorption capacity of Alisma Plantago Aquatica for $\mathrm{Zn}$ (II) increases with increasing temperature. The $\Delta \mathrm{S}$ values are very small which shows the entropic change occurring during adsorption process is negligible. The values of the thermodynamic parameters are tabulated in the Table III.

TABLE III: THERMODYNAMIC PARAMETERS FOR THE ADSORPTION OF ZN(II) ON AP AT VARIOUS TEMPERATURES.

\begin{tabular}{|l|l|l|l|l|l|}
\hline $\mathrm{T}(\mathrm{K})$ & $\mathrm{b}$ & $\Delta \mathrm{G}$ & $\Delta \mathrm{H}$ & $\Delta \mathrm{S}$ & $\mathrm{R}^{2}$ \\
\hline & $\left(\mathrm{Lmol}^{-1}\right)$ & $\left(\mathrm{kJmol}^{-1}\right)$ & $\left(\mathrm{kJmol}^{-1}\right)$ & $\left(\mathrm{kJmol}^{-1} \mathrm{~K}^{-1}\right)$ & \\
\hline 293 & 4570.76 & -20.53 & & & \\
\hline 303 & 4904.25 & -21.41 & 11.364 & 0.1086 & 0.9964 \\
\hline 313 & 5800.10 & -22.55 & & & \\
\hline 323 & 6918.30 & -23.74 & & & \\
\hline
\end{tabular}

\section{Characterization of the Adsorbent}

Fourier transform infrared spectral analysis was carried out in order to identify the different functional groups present in the given samples. The different functional groups which are present in the given samples are $\mathrm{OH}$ stretching, $\mathrm{CH}$ stretching, $\mathrm{C}=\mathrm{C}$ stretching, $\mathrm{C}-\mathrm{O}$ stretching is showed in Fig. 1. FTIR spectrum of given raw AP sample shows a broad and intense peak at $3330.18 \mathrm{~cm}^{-1}$ which can be attributed to the stretching of $\mathrm{O}-\mathrm{H}$ group due to inter and intramolecular hydrogen bonding of polymeric compounds such as alcohols or phenols. The peak observed at $2918 \mathrm{~cm}^{-1}$ was associated with the stretching vibrations of $\mathrm{C}-\mathrm{H}$ bond of methyl, methylene and methoxy groups .The peaks around 
$1600-1627 \mathrm{~cm}^{-1}$ corresponded to the $\mathrm{C}=\mathrm{C}$ stretching which might be attributed to the presence of aromatic or olefinic or $\mathrm{N}-\mathrm{H}$ bending bands. The intense peak at $1000-1031 \mathrm{~cm}^{-1}$ corresponded to the $\mathrm{C}-\mathrm{O}$ stretching of alcohol or carboxylic acid. FTIR spectrum of the given raw AP loaded with $\mathrm{Zn}$ (II) shows that the peaks at $3330,2918,1606,1009 \mathrm{~cm}^{-1}$ (before adsorption) had shifted slightly after binding with zinc as shown in the Table IV. . This was due to the participation of these functional groups in the binding of metal ions. It was also noted that shifting of wave number depends on the concentration of the metal present in the given sample agreed by literature survey.

The scanning electron micrograph revealed the surface texture and morphology of the adsorbent is showed in Fig. 2.

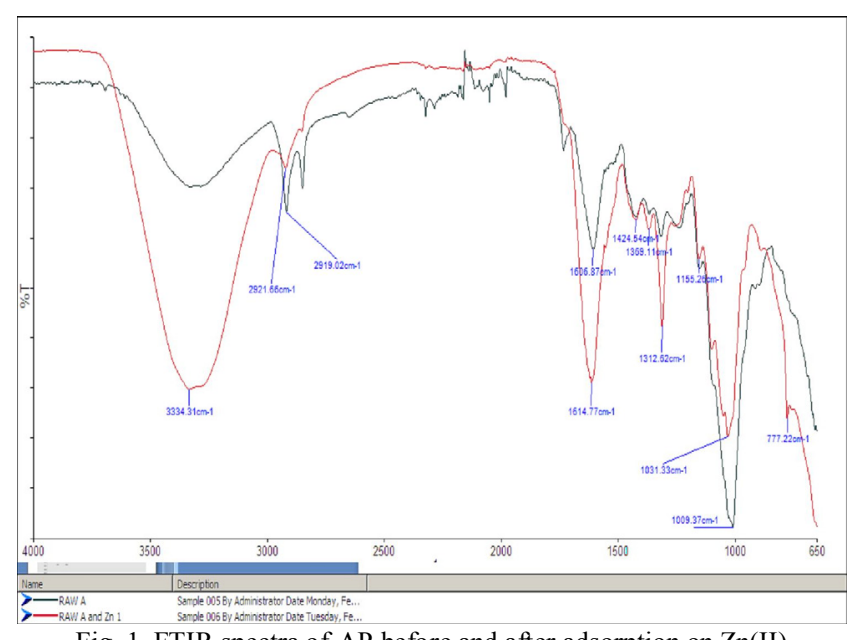

Fig. 1. FTIR spectra of AP before and after adsorption on $\mathrm{Zn}(\mathrm{II})$

TABLE IV: COMPARISON OF FTIR BAND POSITIONS OF RAW ALISMA_AP BEFORE AND AFTER METAL IONS ADSORPTION IN WAVE NUMBER(CM $\left.{ }^{-1}\right)$

\begin{tabular}{|l|l|l|}
\hline Assignment & Raw AP & After adsorption \\
\hline O-H stretching & 3330.18 & 3334.31 \\
\hline C-H stretching & 2918.70 & 2921.66 \\
\hline C $=$ C stretching & 1606.90 & 1614.77 \\
\hline C-O stretching & 1009.48 & 1031.33 \\
\hline
\end{tabular}

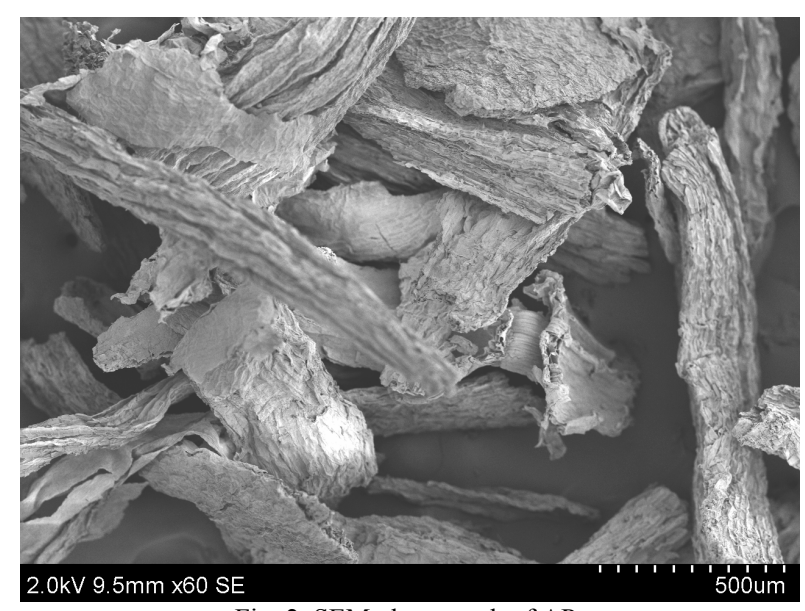

Fig. 2. SEM photograph of AP

\section{E. Continuous Study}

A continuous fixed bed study was carried out using Alisma Plantago Aquatica as a adsorbent for the removal of zinc. In column operation, rate of adsorption depends on the concentration of metal in the solution being treated. As the adsorbent is continuously in contact with fresh metal bearing solution, the concentration of the solution in contact with a given layer of adsorbent in the column is relatively constant. The performance of packed bed column was analysed using the effluent concentration versus time curves. For adsorption, the plot is usually referred to as the breakthrough curve.

The relative concentration of metal ions in treated effluent was plotted as a function of time in the form of breakthrough curves as illustrated by representative data in Fig. 3 -Fig. 4. As the flow rate increases, the breakthrough curves become steeper and the breakpoint time decreases. The flow rate affects the slope of the linear part of the breakthrough curve. Saturation time is also greatly affected by the flow rate. As flow rate is increased, the time required for breakthrough point of zinc uptake decreased. At lower inlet zinc concentration the treated volume was greater.

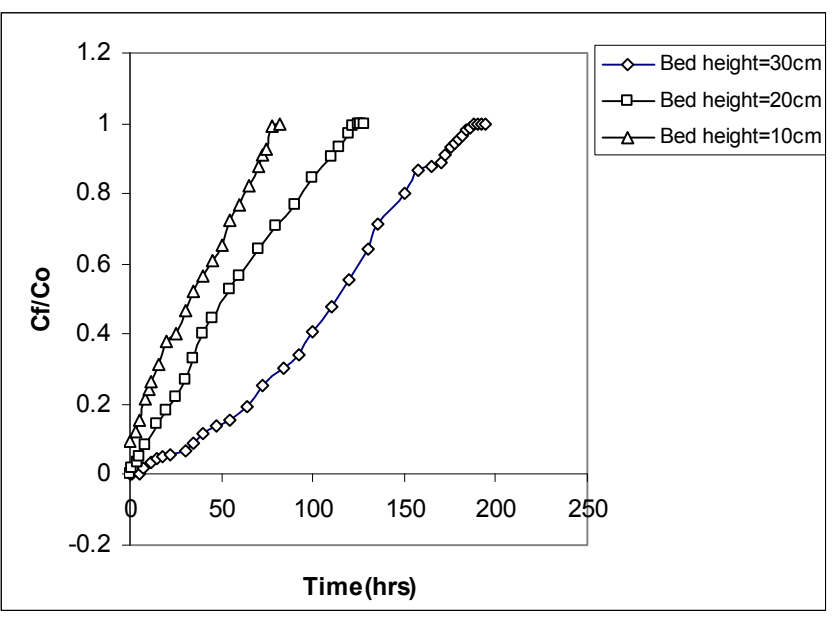

Fig. 3. Breakthrough curves at different bed depths for zinc adsorption. Flow rate $3 \mathrm{ml} / \mathrm{min}, \mathrm{C}_{\mathrm{o}}=10 \mathrm{mg} / \mathrm{l}$

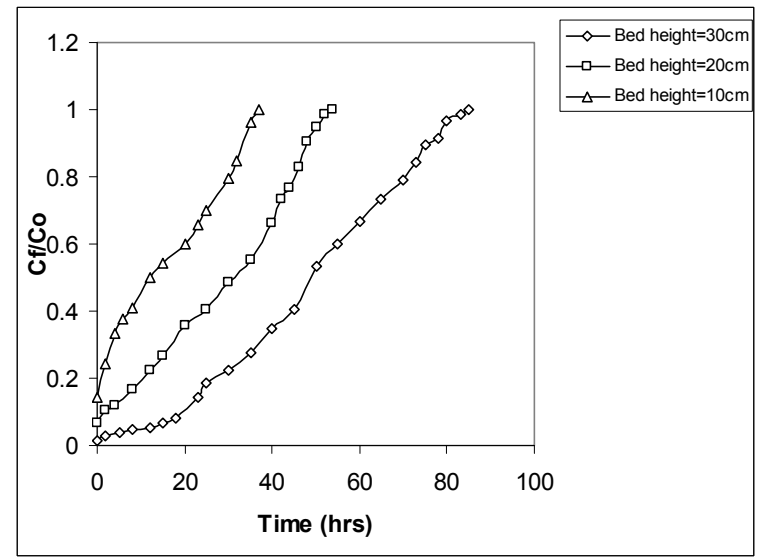

Fig. 4. Breakthrough curves at different bed depths for zinc adsorption. Flow rate $6 \mathrm{ml} / \mathrm{min}, \mathrm{C}_{\mathrm{o}}=10 \mathrm{mg} / \mathrm{l}$

\section{1) Mathematical description}

The performance of packed beds is described through the concept of the breakthrough curve. The time for breakthrough appearance and the shape of the breakthrough curve are very important characteristics for determining the operation and the dynamic response of a adsorption column.

The breakthrough curves show the loading behavior of zinc to be removed from solution in a fixed bed and is usually expressed in terms of adsorbed zinc concentration $\left(C_{a d}\right)=$ 
inlet zinc concentration $\left(C_{o}\right)$ - outlet zinc $\left(C_{f}\right)$

The maximum (equilibrium) capacity of the column for given feed concentration is equal to the area under the plot of the adsorbed metal ion concentration $C_{a d s}$ versus time or the area behind the breakthrough curve. The amount of metal that remains in the effluent, $C_{e q}$, is the area under the breakthrough curve as shown in Fig. 3 -Fig. 4

$$
\begin{aligned}
& C_{\max }=Q \int_{t=0}^{t=t_{\text {total }}} C_{a d} d t \\
& W=Q C_{o} t_{\text {total }} \\
& Y=\frac{C_{\max }}{W} 100
\end{aligned}
$$

In the first stage of removal studies in the continuous flow fixed column with Alisma Plantago Aquatica, the flow rate was changed from $3 \mathrm{ml} / \mathrm{min}$ to $6 \mathrm{ml} / \mathrm{min}$.and the zinc concentration in the feed was kept constant at $10 \mathrm{ppm}$.From the Table $\mathrm{V}$ at the lowest flow rate of $3 \mathrm{ml} / \mathrm{min}$, relatively higher uptake capacity values were observed. From the Table $\mathrm{V}$ at the lowest flow rate of $3 \mathrm{ml} / \mathrm{min}$, relatively higher uptake capacity values were observed. In general the total adsorbed zinc quantity, maximum zinc uptake and zinc removal percentage values decreased with increasing flow rate.

\begin{tabular}{|c|c|c|c|c|c|c|}
\hline $\begin{array}{c}\text { Flow rate } \\
(\mathrm{ml} / \mathrm{min})\end{array}$ & $\begin{array}{l}\text { Conc. } \\
(\mathrm{mg} / \mathrm{l})\end{array}$ & $\begin{array}{c}\text { Bed } \\
\text { depth } \\
(\mathrm{cm})\end{array}$ & $\begin{array}{c}\text { Maximum } \\
\text { equilibrium } \\
\text { capacity }(\mathrm{mg})\end{array}$ & $\begin{array}{c}\text { Metal } \\
\text { loading }(\mathrm{mg})\end{array}$ & $\begin{array}{c}\begin{array}{c}\text { Uptake } \\
\text { capacity } \\
(\mathrm{mg} / \mathrm{gm})\end{array} \\
\end{array}$ & $\begin{array}{c}\text { Yield } \\
(\%)\end{array}$ \\
\hline 3 & 10 & $\begin{array}{l}10 \\
20 \\
30\end{array}$ & $\begin{array}{l}62.0 \\
101.8 \\
223.0\end{array}$ & $\begin{array}{l}147.6 \\
230.4 \\
349.2\end{array}$ & $\begin{array}{l}15.5 \\
12.7 \\
18.6\end{array}$ & $\begin{array}{l}42.0 \\
44.2 \\
63.8\end{array}$ \\
\hline 6 & 10 & $\begin{array}{l}10 \\
20 \\
30\end{array}$ & $\begin{array}{l}51.1 \\
105.0 \\
180.9\end{array}$ & $\begin{array}{l}133.2 \\
194.4 \\
306.0\end{array}$ & $\begin{array}{l}12.8 \\
13.1 \\
15.1\end{array}$ & $\begin{array}{l}38.3 \\
54.0 \\
59.1\end{array}$ \\
\hline
\end{tabular}

TABLE V: EFFECT OF FLOW RATE AND BED DEPTH ON THE ADSORPTION OF ZN(II) BY ALISMA PLANTAGO AQUATICA

\section{2) Application of the Adams -Bohart and Wolborska models}

The fundamental equations describing the relationship between $C / C_{o}$ and $\mathrm{t}$ in flowing systems were established by Adams -Bohart and Wolborska models. Adams -Bohart model is used for the description of the initial part of the breakthrough curve and is given by the following equations, with parameters $k$ and $N_{o}$.

$$
\ln \frac{C}{C_{o}}=k C_{o} t-k N_{o} \frac{Z}{U_{o}}
$$

where $C$ is the solute concentration $(\mathrm{mg} / \mathrm{l}) ; Z$ the bed depth $(\mathrm{cm}) ; k$ the kinetic constant $(1 / \mathrm{mg} \mathrm{hr}) ; U_{o}$ the linear flow rate $(\mathrm{cm} / \mathrm{hr})$, defined as the ratio of the flow rate $Q(\mathrm{ml} / \mathrm{hr})$ to the cross sectional area $A\left(\mathrm{~cm}^{2}\right)$ and $N_{o}$ the saturation concentration (mg/l).

Wolborska model is also used for the description of adsorption dynamics using mass transfer equations for diffusion mechanisms in the range of the low concentration breakthrough curve. The following relationship describes the concentration distribution in the bed for the low concentration region.

$$
\ln \frac{C}{C_{o}}=\frac{\beta C_{o}}{N_{o}} t-\frac{\beta Z}{U_{o}}
$$

where $\beta$ is the coefficient of the external mass transfer $(1 / \mathrm{hr})$. The expression of the Wolborska solution is equivalent to the Adams - Bohart relation if the coefficient $\mathrm{k}$ is equal to $\beta / \mathrm{N}_{\mathrm{o}}$.

Both the model expression can be linearized to give a relationship between $\ln \left(C / C_{o}\right)$ and time from which the model parameters can be calculated. It was observed that the model predictions agreed very closely with experimental data giving a linear relationship up to 50\%breakthough, for all breakthrough curves $\left(R^{2}>0.9\right)$. The model parameters, rate constant $(\mathrm{k})$ or mass transfer coefficient $(\beta)$ and the adsorption capacity $(\mathrm{No})$ were calculated from the slope and intercept of the lines respectively. The values of the Adams -Bohart and Wolborska model parameters corresponding to the experimental conditions and determination coefficient $\left(R^{2}\right)$ are given in the Table VI.

The values shown in table was obtained after applying the respective model equations to the experimental data for varying bed depths zinc adsorption column. However Adams -Bohart and Wolborska model predictions of $N_{o}$ matched well. Although the Adams -Bohart and Wolborska model provides a simple and comprehensive approach to running

\begin{tabular}{|c|c|c|c|c|c|c|c|}
\hline \multirow{2}{*}{$\begin{array}{l}\text { Flow } \\
\text { rate } \\
\mathrm{ml} / \mathrm{min} \text { ) }\end{array}$} & \multirow{2}{*}{$\begin{array}{l}\text { Conc. } \\
(\mathrm{mg} / \mathrm{l})\end{array}$} & \multirow{2}{*}{$\begin{array}{c}\text { Bed } \\
\text { depth } \\
(\mathrm{cm})\end{array}$} & \multicolumn{2}{|c|}{ Adams -Bohart } & \multicolumn{2}{|c|}{ Wolborska } & \multirow[b]{2}{*}{$R^{2}$} \\
\hline & & & $\begin{array}{c}N_{o} \\
(\mathrm{mg} / \mathrm{l})\end{array}$ & $\begin{array}{c}k \\
(1 / \mathrm{mg} \mathrm{hr})\end{array}$ & $\beta(1 / \mathrm{hr})$ & $N_{o}(\mathrm{mg} / \mathrm{l})$ & \\
\hline 3 & 10 & $\begin{array}{l}10 \\
20 \\
30\end{array}$ & $\begin{array}{l}425.32 \\
533.42 \\
641.14\end{array}$ & $\begin{array}{l}0.00763 \\
0.00303 \\
0.00251\end{array}$ & $\begin{array}{l}3.245 \\
1.616 \\
1.609\end{array}$ & $\begin{array}{l}425.30 \\
533.33 \\
641.03\end{array}$ & $\begin{array}{l}0.964 \\
0.975 \\
0.975\end{array}$ \\
\hline 6 & 10 & $\begin{array}{l}10 \\
20 \\
30\end{array}$ & $\begin{array}{l}597.20 \\
695.60 \\
487.62\end{array}$ & $\begin{array}{l}0.00701 \\
0.00439 \\
0.00725\end{array}$ & $\begin{array}{l}4.18 \\
3.05 \\
3.53\end{array}$ & $\begin{array}{l}597.20 \\
695.44 \\
486.89\end{array}$ & $\begin{array}{l}0.949 \\
0.974 \\
0.983\end{array}$ \\
\hline
\end{tabular}
and evaluating adsorption column tests, its validity is limited to the range of conditions used.

TABLE VI: ADAMS -BOHART AND WOLBORSKA MODEL PARAMETERS CORRESPONDING TO EXPERIMENTAL CONDITIONS

\section{CONCLUSION}

This study indicates that Alisma Plantago Aquatica which is low cost, can be used as an efficient biosorbent material for removal of $\mathrm{Zn}$ (II) from wastewater. The adsorption isotherms at different temperatures could be well described by the three isotherm models. IR spectrum analysis suggested the different functional groups which are present in the given sample. The thermodynamic study shows that the adsorption of $\mathrm{Zn}(\mathrm{II})$ was endothermic in nature. The negative values of $\Delta G$ reveal the feasibility and spontaneous nature of the process. The performance of packed column was described through the concept of breakthrough and the values of column parameters predicted as a function of bed depth. Column studies showed good agreement between the experimental data obtained with Adams - Bohart or Wolborska model. 


\section{ACKNOWLEDGMENT}

The authors wish to acknowledge the support given by the Centre for Engineering Research and Development (CERD), Thiruvananthapuram for providing financial support.

\section{REFERENCES}

[1] P. Suksabye, A. Nakajima, P. Thiravetyan, Y. Baba, and Nakbanpote, "Mechanism of $\mathrm{Cr}(\mathrm{VI})$ adsorption by coir pith studied by ESR and adsorption kinetic," Journal of Hazardous Materials, vol. 161, no. 2-3, pp. 1103-1108, January 2009.

[2] W. S. Wan Ngah and M. A. K. M. Hanfiah, "Removal of heavy metal ions from wastewater by chemically modified plant wastes as adsorbents: A review," Journal of Bioresourse Technology, vol. 99, no. 10, pp. 3935-3948, July 2008.

[3] O. S. Amuda, A. A. Giwa, and IA. Bello, "Removal of heavy metal from industrial wastewater using modified activated coconut shell carbon," Journal of Biochemical Engineering, vol. 36, no. 2, pp 174-181, September 2007.

[4] Y. Mustafa, F. Gode, E. Pehlivan, S. Ozmert, and Y. C. Sharma, "An economic removal of $\mathrm{Cu} 2+$ and $\mathrm{Cr} 3+$ on the new adsorbents: Pumice and polyacrylonitrile/ pumice composite," Chemical Engineering Journal, vol. 137, no. 3, pp. 453-461, April 2008.

[5] S. Cetin and E. Pehlivan, "The use of fly ash as a low cost, environmentally friendly alternative to activated carbon for the removal of heavy metals from aqueous solutions," Colloids and surfaces, vol. 1-2, pp. 83-87, April 2007.

[6] B. Bayat, "Comparative study of adsorption properties of Turkish fly ashes: II. The case of chromium (VI) and cadmium (II)," Journal of Hazardous Materials, vol. 95, no.3, pp. 275- 290, December 2002

[7] O. Abdelwahab, "Kinetics and isotherm studies of copper (II) removal from wastewater using various adsorbents," Egyptian Journal of Aquatic Research, vol. 33, no. 1, pp. 125-143, 2007.

[8] S. Larous, A. H. Meniai, and M. B. Lehocine, "Experimental study of the removal of copper from aqueous solution by adsorption using sawdust," Desalination, vol. 185, no. 1-3, pp. 483-490, November 2005.

[9] M. Uysal and I. Ar, "Removal of $\mathrm{Cr}(\mathrm{VI})$ from industrial waste waters by adsorption: part I: Determination of optimum conditions," J. Hazard. Mater., vol. 149, no. 2, pp. 482-491, April 2007.

[10] B. C. Qi and C. Aldrich, "Biosorption of heavy metals from aqueous solutions with tobacco dust," Journal of Bioresource Technology, vol. 99, no.13, pp. 5595-5601, September 2008.

[11] E. Atalay, F. Gode and Y. C. Sharma, "Removal of selected toxic metals by a modified adsorbent," Practice periodical of hazardous toxic and radioactive waste management, vol. 14, no. 2, pp. 132-138, April 2010.

[12] K. K. Krishnani, X. G. Meng, C. Christodoulatos, and V. M. Boddu , "Biosorption mechanism of nine different heavy metals onto biomatrix from rice husk," Journal of Hazardous Materials, vol. 53, no. 3, pp. 1222-1234, May 2008.

[13] A. K. Meera, K. Kadirvelu, G. K. Mishra, C. Rajagopal, P. N. Nagar, "Adsorptive removal of heavy metals from aqueous solution by treated sawdust," Journal of Hazardous Materials, vol. 150, no. 3, pp. 604-611, February 2008.

[14] M. E. Argun, S. Dursun, C. Ozdemir, and M. Karatas, "Heavy metal adsorption by modified oak sawdust: Thermodynamics and kinetics," Journal of Hazardous Materials, vol. 141, pp. 77-85, 2007.

[15] B. Yu, Y. Zhang, A. Shukla, S. S. hukla, and K. L. Dorris, "The removal of heavy metal from aqueous solutions by sawdus adsorption-removal of copper," Journal of Hazardous Materials, vol. 80, no.1-3. pp. 33-42, December 2000.

[16] A. H. Mahvi, D. Naghipour, F. Vaezi, and S. Nazmara, "Teawaste as An Adsorbent for Heavy Metal Removal from Industrial Wastewaters," American Journal of Applied Sciences, vol. 2, pp. 372-375, 2005.

[17] C. Escudero, C. Gabaldon, P. Marzal, and I. Villaescusa, "Effect of EDTA on divalent metal adsorption onto grape stalk and exhausted coffee wastes," Jovurnal of Hazardous Materials, vol. 152, no. 2, pp.476-485, April 2008.

[18] B. M. W. P. K. Amarasinghe and R. A. Williams, "Tea waste as a low cost adsorbent for the removal of $\mathrm{Cu}$ and $\mathrm{Pb}$ from wastewater," Chemical Engineering Journal, vol. 132, no. 1-3, pp. 299-309, August 2007.

[19] F. Gonen and D. S. Serin, "Adsorption study on orange peel: Removal of $\mathrm{Ni}(\mathrm{II})$ ions from aqueous solution," African Journal of Biotechnology, vol. 11, no. 5, pp. 1250-1258, January 2012.

[20] Q. Li, J. P. Zhai, W. Y. Zhang, M. Wang, and J. Zhou, "Kinetic studies of adsorption of $\mathrm{Pb}$ (II), $\mathrm{Cr}$ (II) and $\mathrm{Cu}$ (II) from aqueous solution by sawdust and modified peanut husk," Journal of Hazardous Materials, vol. 141, no. 1, pp. 163-167, March 2007.

[21] K. Kadirvelu, K. Thamaraiselvi. C, and Namasivayam, "Removal of heavy metals from industrial wastewaters by adsorption onto activated carbon prepared from an agricultural solid waste," Journal of Bioresource Technology, vol. 76, pp. 63-65, January 2001.

[22] G. Issabayeva, M. K. Aroua, and N. M. Sulaiman, "Continuous adsorption of lead ions in a column packed with palm shell activated carbon," Journal of Hazardous Materials, vol. 155, no. 1-2, pp. 109-113, June 2008.

[23] H. Benhima, M. Chiban, F. Sinan, P. Seta, and M. Persin, "Removal of lead and Cadmium ions from aqueous solution by adsorption onto micro-particles of dry plants," Journal of Colloids and Surfaces, vol. 61, no. 1, pp. 10-16, June 2008.

[24] P. King, P. Srinivas, Y. P. Kumar, V. S. R. K. Prasad, "Sorption of copper(II) ions from aqueous solution by Tectona grandis (Teak leaves powder)," Journal of Hazardous Materials, vol. 136, no. 3, pp. 560-566, January 2006.

[25] P. Venkateswarlu, M. V. Ratnam, D. S. Rao, and M. V. Rao, "Removal of chromium from an aqueous solution using Azadirachta indica (neem) leaf powder as an adsorbent," International Journal of Physical Sciences, vol. 2, no. 8, pp. 188-195, July 2007.

[26] E Valdman, L Erijman, F. L. P. Pessoa, and S. G. F. Leite, "Continuous biosorption of $\mathrm{Cu}$ and $\mathrm{Zn}$ by immobilized waste biomass Sargassum sp.," Process Biochem., vol. 36, no. 8-9, pp. 869-873, March 2001.

[27] G Issabayeva, M. K. Aroua, and N. M. Sulaiman, "Continuous adsorption of lead ions in a column packed with palm shell activated carbon," Journal of Hazardous Materials, vol. 155, no.1-2, pp. 109-113, November 2008.

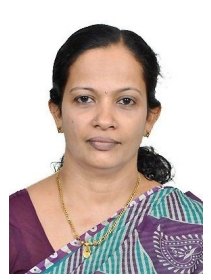

E. R. Ushakumary received the Bachelor's degree in Chemical Engineering from Government Engineering College, Thrissur, Kerala, India and the Master's degree in Chemical Engineering with Environmental Engineering specialization from the Indian Institute of Technology (IIT) Madras, Chennai. She has about 13 years of experience in teaching. She started her career as Lecturer in Chemical Engineering, Government Engineering College, Thrissur, Kerala, India. She is currently the Associate Professor in the department of Chemical Engineering, Government Engineering College Kozhikode, Kerala, India.. Her areas of interest include Environmental Engineering, Food and preservatives, Optimization of chemical processes.

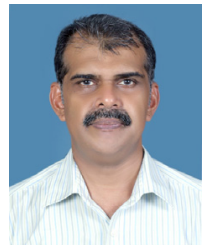

G. Madhu is a professor in the Department of Safety Engineering and Chemical Engineering in the School of Engineering of Cochin University of Science and Technology. He has more than 18 years of industrial experience in process plant operation and design, environmental engineering and management and process safety engineering. He received the Young Scientist Award in 1994 and Platinum Jubilee Award (2010) of the Institution of Engineers (India) - Karnataka State for meritorious services to chemical and safety engineering. He has guided $21 \mathrm{PhD}$ and $38 \mathrm{MTech}$ students. He has more than 120 papers in international/national journals and conferences. He has been associated with several professional bodies. 